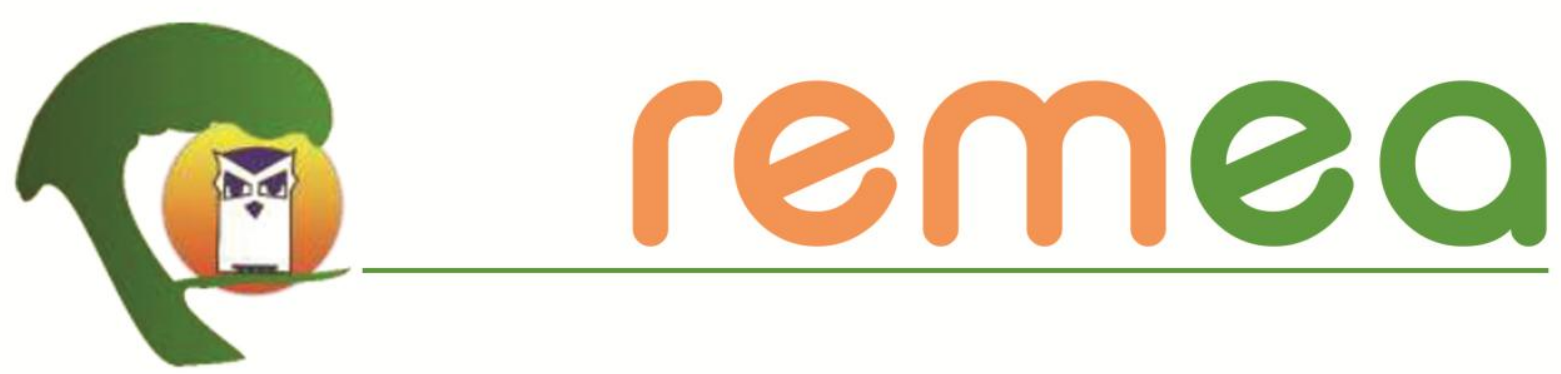

\title{
Possibilidades potentes para a formação de educadores ambientais: a "ComVivência Pedagógica"
}

\author{
Jeniffer de Souza Faria ${ }^{1}$ \\ Universidade Federal Rural do Rio de Janeiro - UFRRJ \\ ORCID: https://orcid.org/0000-0003-4230-5147 \\ Mauro Guimarães ${ }^{2}$ \\ Universidade Federal Rural do Rio de Janeiro - UFRRJ \\ ORCID: https://orcid.org/0000-0002-4158-313X
}

Resumo: Este artigo emerge reflexões sobre a formação de educadores ambientais, em uma perspectiva radical, diante da grave crise socioambiental que se mostra civilizatória. Apresenta-se a proposta teóricametodológica da ComVivência Pedagógica, explicitando sua base nos cinco princípios formativos e outros elementos que a compõe como o ambiente educativo, a experiência significativa e a potência na transformação do educador como um "Ser mais ambiental". A partir dos diálogos estabelecidos e dos saberes cocriados no desenvolvimento de experiências formativas anteriores, longe de sermos conclusivos, consolidamos conceitos e elencamos algumas pistas que contribuem para que novas propostas sejam desenvolvidas e suas especificidades possam ser articuladas.

Palavras-chave: Educação ambiental. Processos Formativos. ComVivência Pedagógica.

\section{Potentes posibilidades para la formación de educadores ambientales: la "ComVivência Pedagógica"}

Resumen: Este artículo surge de reflexiones sobre la formación de educadores ambientales, en una perspectiva radical, ante la grave crisis socioambiental que se ha mostrado civilizadora. Se presenta la propuesta teóricometodológica de ComVivência Pedagógica, explicando su base en los cinco principios formativos y otros elementos que la componen, como el entorno educativo, la experiencia significativa y el poder de transformar al educador en un Ser más ambiental. A partir de diálogos establecidos y saberes co-creados en el desarrollo de experiencias formativas previas, lejos de ser concluyentes, consolidamos conceptos y enumeramos algunas pistas que contribuyen a que se desarrollen nuevas propuestas y se articulen sus especificidades.

Palabras-clave: Educación ambiental. Procesos formativos. ComVivência Pedagógica.

\section{Powerful possibilities for the training of environmental}

1 Graduada em Pedagogia. Mestrado (UFJF) e doutorado (UFRRJ) (2021) em Educação. E-mail: jenidocumentos@gmail.com

${ }^{2}$ Graduado em Geografia. Mestre em Educação (UFF). Doutor em Ciências Sociais (UFRRJ). Professor do Programa de Pós-Graduação em Educação (UFRRJ). E-mail: guimamauro@hotmail.com 
Abstract: This article emerges from reflections on the training of environmental educators, in a radical perspective, in view of the serious socio-environmental crisis that has shown itself to be civilizing. The theoretical-methodological proposal of ComVivência Pedagógica is presented, explaining its basis in the five formative principles and other elements that compose it, such as the educational environment, the significant experience and the power in transforming the educator as a more environmental Being. From established dialogues and knowledge co-created in the development of previous formative experiences, far from being conclusive, we consolidate concepts and list some clues that contribute to new proposals to be developed and their specificities to be articulated.

Keywords: Environmental education. Formative Processes. ComVivência Pedagógica.

\section{Introdução}

Vivemos tempos de crise! Vários estudos ${ }^{3}$ apontam para a atual e gravíssima degradação socioambiental planetária, consequência do como a sociedade moderna globalizada vem estabelecendo seu modo de vida, a partir de relações disjuntivas que geram dominação e exploração sobre a natureza. Pandemia, mudanças climáticas, miséria, refugiados, exclusão de vulneráveis, alguns dos evidentes reflexos de uma crise socioambiental que se mostra civilizatória. Temos hoje um real e inédito risco de colapsar de tal forma as condições ambientais, em que a vida humana, quiçá planetária, não terão condições de se manterem.

Ao partir da compreensão da urgência dessa situação, explicita-se a emergência nas medidas de enfrentamento. Para nós a Educação Ambiental, a partir da práxis de educadores, torna-se uma das atividades fundamentais para a construção de novas relações sustentáveis entre sociedade e natureza. Porém, acreditamos que esse enfrentamento se dê por uma concepção crítica, transformadora e emancipatória de Educação Ambiental que supere a concepção hegemônica de Educação conservadora na sociedade brasileira e mundial. Pois a emergência da situação e urgência da construção de novas relações entre sociedade e natureza, nos induz a defendermos a necessidade de uma formação radical (que vai à raiz do problema) de educadores ambientais que possam ser, como educadores transformados e transformadores, sujeitos dinamizadores que potencializem processos de transformação da realidade socioambiental.

\footnotetext{
${ }^{3} \mathrm{O}$ mais recente e amplo estudo que traz sérios indicativos da gravidade da situação ambiental é o relatório do IPCC 2021 - Climate Change 2021: The Physical Science Basis.
} 
Para tanto, as reflexões que apresentamos neste artigo emergiram dos estudos de Faria (2021) com base em experiência formativa realizada para pesquisa e outras publicadas anteriormente ${ }^{4}$, referenciando a construção coletiva do Grupo de Estudos e Pesquisa em Educação Ambiental, Diversidade e Sustentabilidade (GEPEADS ${ }^{5} /$ UFRRJ) de uma proposta

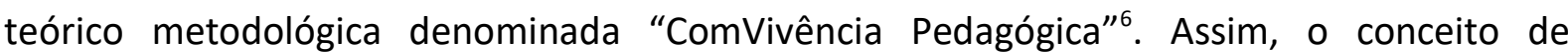
ComVivência Pedagógica vêm contribuir para o campo da educação ambiental, principalmente no que se refere aos avanços já consolidados e publicados em termos de propostas formativas, reforçando a necessidade de avançar nas perspectivas superficiais e fragmentadas de formação.

\section{Transformações necessárias}

Guimarães (2004b) identificou que professores, mesmo sensibilizados pelas questões ambientais e de forma bem intencionada, ao trabalharem com seus alunos tinham suas práticas pedagógicas fragilizadas por não provocarem transformações significativas em suas realidades mais próximas. Nesse estudo identificaram-se professores presos a uma "armadilha paradigmática" e desse indicativo se concluiu a importância de uma formação de educadores que seja propícia à ruptura dessas armadilhas para a práxis de uma Educação crítica, transformadora e emancipatória.

Para romper com o movimento formativo ingênuo e que reproduz, inconscientemente, uma forma única de ver o mundo, "é preciso se abrir para outras leituras

\footnotetext{
${ }^{4}$ Guimarães e Medeiros (2016); Granier (2017); Nunes (2019); Cruz (2019); Guimarães, Granier e Klein (2020); Guimarães e Meira (2020); Éder (2021), dentre outros.

${ }^{5} \mathrm{Em} 17$ anos de atuação, o Grupo busca aprofundamento nos estudos sobre as diferentes possibilidades do campo da Educação Ambiental, ancorados na vertente crítica da EA. Além disso, desenvolve projetos de pesquisa e extensão em articulação com outros grupos. Atualmente preocupa-se com a formação de educadores ambientais e com a proposição/construção de políticas públicas capazes de efetivar ações nas práticas cotidianas dos diferentes atores envolvidos, constituindo, assim um aporte teórico-metodológico que denominamos ComVivência Pedagógica. Para saber mais, visite nosso blog https://gepeadsim.wordpress.com/ ${ }^{6}$ A "ComVivência Pedagógica" é uma proposta teórica metodológica de formação de educadores ambientais, em desenvolvimento por integrantes do Grupo de Estudos e Pesquisas em Educação Ambiental, Diversidade e Sustentabilidade (GEPEADS) da Universidade Federal Rural do Rio de Janeiro. É um processo formativo pela qual se constitui um ambiente educativo que se constrói em uma práxis pedagógica de educadores ambientais em formação, na convivência imersiva com outros grupos humanos com modos de vida diversos da modernidade. Propõe-se um "choque de realidade" pela radicalidade de experiências vivenciais em outros referenciais epistemológicos e modos de vida, em um exercício de dialogicidade em novas relações conectivas com o outro, com o mundo.
} 
que nos inspirem na diversidade e vitalizem a sermos e fazermos diferente". Mediante essas premissas, Guimarães e Medeiros (2016, p. 53) incitam o estranhamento da visão dominante pela reflexão crítica para que pela práxis, fundamentada no coletivo, haja novas "condições concretas e simbólicas que permitam a percepção e vivência de uma experiência pedagógica diferenciada".

É nesse contexto que podemos observar e defendemos uma "ComVivência Pedagógica" com outras referências epistemológicas para fomentar outras formas de se relacionar entre nós e com a natureza. Esse exercício formativo que requer humildade, solidariedade, compartilhamento e amorosidade pode-se fazer no processo de aproximação, participação e convívio com as memórias, crenças e costumes de povos e comunidades tradicionais que praticam constantemente e ativamente suas manifestações culturais como dança, gastronomia, música, arte, ritos e temporalidade.

Almeida et al (2017, p.10) salientam que os saberes presentes e gerados a partir do intercâmbio de experiências têm por objetivo "potencializar as produções históricas de outras maneiras de compreender a natureza", além de dar visibilidade aos saberes silenciados, desvalorizados, "postos às margens e não reconhecidos pelas epistemologias hegemônicas". Ao nos despir das noções preconceituosas e nos colocarmos em dialogicidade, acreditamos ser "extremamente pedagógica e formativa essa convivência para a educação ambiental crítica, transformadora e emancipatória" (GUIMARÃES; MEDEIROS, 2016, p.54)

Conforme Candido et al (2017) aponta "não há um único paradigma para se alcançar uma sociedade do bem estar. Essas comunidades, porém, representam por meio da educação ambiental uma possibilidade relevante de avanço em relação à sustentabilidade para a cultura hegemônica capitalista" que em seu discurso, exclui práticas e crenças dos povos e comunidades tradicionais. (CASTOR, 2019).

Nessa circunstância, reforça-se a reflexão crítica sobre a dominação epistemológica da modernidade, bem como a necessidade de conhecermos e aplicarmos práticas e representações outras e, assim, "renovar os processos formativos na educação brasileira, destacando o ambiente educativo e a ativação da consciência como pilares desta construção" (CRUZ; GUIMARÃES, 2017, p. 11). 
Conclusivamente, nas palavras de Castor $(2019$, p. 1)

\begin{abstract}
a educação ambiental encontra sinergia com os valores dos povos [e comunidades tradicionais], percebidos em dimensões como a circularidade, a oralidade, a corporeidade, a ludicidade, a memória, a ancestralidade, o Axé, a religiosidade, a musicalidade, a cooperação e o comunitarismo, dimensões que potencializam outro processo civilizatório.
\end{abstract}

Tendo essas considerações, podemos dissertar sobre as possibilidades de uma proposta teórico-metodológica para formar educadores ambientais críticos pela convivência com outras culturas e construção de outros referenciais epistemológicos para balizar uma práxis pedagógica transformadora.

\title{
Educação Ambiental Crítica e Processo Formativo Significativo
}

As perspectivas contemporâneas que utilizam da educação como mecanismo de reprodução e permanência do modelo de desenvolvimento econômico ressaltam que as teorias e práticas que conhecemos devem se ajustar à "sociedade do conhecimento" em que vivemos.

O termo "sociedade do conhecimento" se configura com um arsenal da modernidade para afirmar a sociabilidade do capital, marcada pelos impactos da tecnologia na vida cotidiana, como, por exemplo, das "informações abundantes, caóticas e dispersas, em que as imagens visuais prevalecem sobre a linguagem verbal, oral e escrita, mas também pela competição e interpretações parciais de processos complexos" (FRIGOTTO; CIAVATTA, 2013, p. 118). A tese dos autores é complementada por outros como, por exemplo, Morin (1997) que explana sobre o paradigma disjuntivo, o qual afirma que a percepção da realidade se encontra fragmentada e reduzida. Numa perspectiva dicotomizada, a forma de organização da modernidade não é questionada, problematizada, ressignificada ou ampliada, mas é enfaticamente reproduzida numa armadilha paradigmática, na maior parte das vezes presa inconscientemente em uma dinâmica que limita a compreensão da realidade.

Nesse contexto, indivíduo e coletivo se colocam separados, as mudanças nas relações humanas liquefeitas as tornam superficiais e fragilizadas, conforme os apontamentos de Bauman (2001; 2004). Os padrões clássicos, códigos sociais e culturais de referência do passado que estruturavam o projeto de vida coletivo se perdem, liquefazem. A esfera do 
trabalho também é afetada com empregos temporários, meia jornada e subempregos. No campo das relações, as conexões se tornaram mais frágeis. Os seres humanos se tornaram mercadorias que podem ser consumidas e descartadas ou excluídas a qualquer momento.

As redes sociais também podem nos instigar diariamente a "viver para fora", em intensa acumulação de parceiros e amigos transformando a vida cotidiana em um espetáculo. A educação, por sua vez, se não estiver atenta a esses efeitos e trabalhar de forma crítica pode se tornar meio de propagação desse modo de viver organizado pela modernidade, nos mantendo inconscientemente presos às referências disjuntivas.

Por isso é preciso refletir sobre as formas como os sujeitos têm estabelecido relações consigo, com o outro e com o mundo, bem como sobre as implicações socioculturais das tecnologias na modernidade. Vislumbrar novos horizontes mentais sobre a essência do ser humano e as relações sociais, as formas de linguagem e de comunicação, das desigualdades, exploração, organização da sociedade, da cultura, do virtual, do excesso de informação, da falta de tempo, bem como do paradigma dominante que determina o "caminho único" a ser seguido e que, por conseguinte, desconsidera e/ou subjuga qualquer conhecimento alternativo (FARIA, 2021).

É nesse cenário tenso e controverso que constatamos a urgência na transformação dos processos educativos para formar potenciais educadores ambientais, conscientes e ativos que possam contribuir com a ruptura da armadilha paradigmática em que estamos imersos. "Romper com as características conservadoras e adotar um posicionamento de permanente questionamento com vistas a construir conhecimentos que sirvam para a emancipação e para a transformação da sociedade é a finalidade primeira da teoria crítica" (LOUREIRO, 2020, p. 80-82). E no que se refere à questão ambiental, cabe analisar e denunciar os projetos de dominação e degradação da natureza, bem como mobilizar e debater sobre os rumos da sociedade de consumo e de todas as "verdades" que estagnam pensamento, a prática educativa e política e ameaça a continuidade da vida planetária.

\section{Sobre a proposta teórico-metodológica ComVivência Pedagógica e os cinco princípios formativos}


A partir dessa demanda, uma abordagem teórico-metodológica está sendo desenvolvida para a formação de educadores ambientais, baseada em vivência coletiva de outros referenciais, onde 0 ambiente educativo ${ }^{7}$ é construído sob uma perspectiva integrativa e não disjuntiva.

A abordagem da ComVivência Pedagógica busca subsidiar os educadores com uma visão crítica da problemática socioambiental e, pela convivência com outros grupos humanos silenciados na modernidade, desencadear um movimento de desconstrução dos padrões estabelecidos para a construção de outros referenciais epistemológicos. (GUIMARÃES; GRANIER, 2017).

Noutras palavras, defendemos que a partir de ambientes potencialmente educativos, subsidiados em outras epistemologias, é possível proporcionar experiências significativas que superem uma perspectiva de formação de instrutores com base em uma teoria e prática superficial, acrítica e fragmentada para tratar das questões socioambientais.

Podemos perceber que a complexidade da problemática socioambiental gera processos igualmente complexos na formação de educadores ambientais. (GRANIER, 2017, p. 117). Neste sentido, Leff (2008, apud GRANIER, 2017, p. 117), ressalta a importância de se buscarem caminhos metodológicos inovadores, para a construção de um conhecimento híbrido, com espaço para diferentes saberes, e que promova o engajamento crítico do educador nas questões contemporâneas, considerando ainda que, para avançarmos em direção a um maior equilíbrio socioambiental, é vital que haja uma transformação das relações entre os seres humanos e destes com a natureza. Neste sentido, mostra-se pertinente que sejam oportunizadas, em processos formativos de educadores ambientais, experiências de reencontro com o natural.

Em complementação a estas observações, e num movimento de romper com o paradigma disjuntivo e a visão antropocêntrica de mundo, mostra-se essencial também à formação do educador ambiental o desenvolvimento do sentido de pertencimento ao coletivo, à natureza, ao cosmos; ser parte no todo. Entretanto, para que isso aconteça, "é

\footnotetext{
${ }^{7}$ Um ambiente educativo significativo tem por objetivo instituir uma dinâmica provocada por princípios formativos da ComVivência Pedagógica numa perspectiva integrativa a partir de outras epistemologias, temporalidade e espaços. Propiciar uma experiência significativa que seja transformadora de pensamento e postura do educador em formação, constituído no coletivo. (FARIA, 2021)
} 
inevitável passar pela construção de relações dialógicas, o que por sua vez, passa pela amorosidade, que está relacionada ao amor pelos seres humanos e pelo mundo". (GRANIER, 2017, p. 115).

Segundo Maturana (2002), a amorosidade ao impor-se como condição humana essencial na formação social permite o estabelecimento de relações fundadas na dialogicidade, no acolhimento, na solidariedade, entre seres humanos e destes com o mundo. A dimensão humanizadora da amorosidade é, portanto, potencialmente transformadora, ao oferecer possibilidades reconstrutoras das relações, que sob bases menos materialistas e mais afetivas, dialógicas e conectivas permitam a instauração de um movimento de cooperação para a superação das situações limites, conforme nos orienta Freire (2016).

A intencionalidade que se expressa na amorosidade articulada à postura dialógica, torna-se a base para o desenvolvimento do Sujeito Ecológico conforme aponta Carvalho (2013). Sobre essa concepção, grosso modo, podemos dizer que se trata de uma perspectiva de vida, com comportamentos, preferências e ações adotadas paulatinamente e caracterizadas pela preocupação com o que é humano e não humano, "mesmo sabendo que os riscos ambientais não se resolvem imediatamente com ações exemplares" (p. 1).

Inspirada em Hannah Arendt, Carvalho (2011) se apoia no plano filosófico para ampliar o debate sobre o comportamentalismo. Para a filósofa "é a ideia de ação que caracteriza a condição humana". Nesse sentido, é na convivência, nas relações que estabelecemos entre pares que influenciamos e criamos novas formas de ser, estar, fazer, sentir no mundo que temos em comum.

De tal modo, um jeito cuidadoso de vida é adotado com práticas éticas, solidárias, responsáveis, amorosas e respeitosas. Este cenário consolida uma dimensão ecológica que pode ser assumida individualmente, em grupos ou por instituições. De acordo com Carvalho (2013, p. 1) "a identificação social e individual com esses valores ecológicos é um processo 
formativo que se desenvolvido a todo o momento, dentro e fora da escola" pode constituir a formação de um Ser Mais Ambiental ${ }^{8}$.

A partir desses pressupostos entendemos que imersos em um movimento formativo vivencial, ou seja, em uma experiência de grande impacto, cinco princípios se colocam fundamentais para subsidiar ou provocar a dinâmica desse ambiente educativo significativo. Esses serão apresentados a seguir.

A reflexão crítica ou pensar criticamente é dar sentido, questionar, silenciar ativo, romper com a racionalidade implicada em um paradigma hegemônico. Considerar e valorizar outros saberes, tempos, espaços, culturas, dinâmicas, organização e tradições.

A ação provocada por esse tipo de movimento reflexivo desvela as relações de poder geradoras de dominação e exploração, transforma e passa a combater a padronização de comportamentos, a normalização, o conformismo, a passividade, a fragmentação, o isolamento e a homogeneização presente na vida moderna que restringe as possibilidades de agir e interferir dos grupos sociais.

Para romper com as certezas, com a forma única de pensar e dar outro sentido às coisas, o sujeito precisa estar aberto ao novo, disponível a experiências, motivado por uma desestabilização criativa. Este princípio está relacionado a experiências de vida, a como ela nos atravessa, aos sentidos e significados que instituímos de forma única e no coletivo para afrontar as certezas do mundo moderno. De acordo com Larrosa (2002) nunca se passaram tantas coisas, mas o nosso mundo atual carece de experiência. Informação não é experiência é, talvez, o oposto. "Experiência é o que nos passa, o que nos acontece, o que nos toca" (p. 21). O sujeito da informação sabe muitas coisas, mas nada the acontece.

Aqui não se trata de afirmar que informação não é importante, mas a forma como o sujeito tem, ou não, feito uso dela é o que nos preocupa. A partir do momento que a informação se torna suficiente por si como realidade, não há espaço para a experiência e nos tornamos cada vez menos disponíveis para compreender a realidade de outra forma, pois

\footnotetext{
${ }^{8}$ Conceito apresentado por Granier (2017, p. 55-59), o qual integra a concepção de Ser Natural como a parte dos indivíduos que se mantém em conexão com a natureza e leva uma vida mais simples, e o Ser Mais, do ponto de vista ontológico colocado por Paulo Freire (2016, p. 85 e 112), como aquele que luta pela humanização, que impõe a superação da alienação, buscando Ser Mais expressivo e ativo no mundo. "O Ser Mais se expressa como ser sujeito, que se sabe no mundo numa presença ativa. Presença "que se pensa a si mesma [...] que intervém, transforma, [...] valora, que decide, que rompe" (GRANIER, 2017, p. 58).
} 
nos apegamos à informação como caminho único. É no diálogo vivenciado que o saber da experiência nasce e transforma modos de vida - sentir, ver e estar no mundo.

Por conseguinte, por meio dele, é possível instituir ações, práticas, mudanças nos padrões pré-estabelecidos pela sociedade. Nas palavras de Freire e Shor (2008, p. 123), "através do diálogo, refletindo juntos sobre o que sabemos e não sabemos, podemos, a seguir, atuar criticamente para transformar a realidade".

Experimentar exige também desacelerar, respirar, observar, silenciar, quiçá, parar o tempo que nos atropela e não nos deixa refletir, trocar, conectar. Por isso, uma postura conectiva é outro princípio que demanda estarmos cada vez mais disponíveis para perceber outras possibilidades de vida no mundo. Compreender que somos parte da natureza e não apenas ocupamos o mundo com privilégios sobre a natureza. Postura necessária ao desenvolvimento humano, pois permite a reflexão sobre a realidade tal como os seres humanos fazem e refazem, afirmando ou contestando as relações entre as pessoas. Uma dimensão assumida individualmente, em grupos ou por instituições em prol do cuidado com/do o todo.

Essencialmente, esse princípio remete a estar ativo, presente no e com o mundo, com o outro e consigo mesmo. Isso implica em sentir-nos imersos no mundo, num mundo que ultrapassa a simples realidade física e palpável por meio de instrumentos mecânicos. Trata-se de sentir-nos como parte de uma rede que nos une aos demais, seja a natureza, os seres humanos, o cosmos, e nos convida a um encontro conosco mesmos enquanto seres racionais e espirituais.

Para alcançarmos essa cosmovisão, podemos realizar diversas práticas e técnicas não disjuntivas para proporcionar aos sujeitos uma profunda reflexão/ação sobre si e uma experiência singular que o modifica a ponto de promover uma vida mais saudável e equilibrada.

No contexto em que este princípio se coloca, ou seja, em processos formativos, conforme Guimarães e Granier (2017, p. 1591) apresentam, podemos inferir que a "dialogicidade viabiliza a construção de relações pautadas na horizontalidade e reciprocidade, onde as experiências e convivências se desdobram em momentos de reflexão individual e coletiva, proporcionando a práxis". Isso quer dizer que o diálogo impõe o desafio 
entre a certeza e incerteza e nesse movimento libertador permite a democratização em todos os aspectos da convivência diária, nas relações humanas que estabelecemos, por meio da comunicação.

Conquistar a liberdade, o respeito à diversidade e à alteridade na coexistência do ser humano na contemporaneidade passam a ser premissas de uma transformação intencional para que o sujeito se torne ator de sua própria história, imerso em uma ordem social com vínculos, raízes, identidade, que demanda mudanças e transformações para superar o comportamento padronizado, a felicidade adaptativa, a satisfação ilusória de uma sociedade que ameaça com a exclusão se infligirmos as normas.

Portanto, se faz necessário formar sujeitos conscientes da crise, da necessidade de transformação e das possibilidades de ação para que sinta a necessidade e perceba que lutar vale a pena (CARVALHO, 2011, p. 189). Esta intencionalidade transformadora é outro princípio a ser desenvolvido que requer uma postura ativa e conectiva do sujeito para que seja "capaz de identificar problemas e participar dos destinos e decisões que afetam seu campo de existência individual e coletivo" (idem, p. 187).

Logo, chamamos atenção para a diferença entre agir e comportar-se. Esta constatação possui relação direta com o campo da EA enquanto prática social e política que tem como finalidade transformar a realidade. Assim, em termos práticos, a EA e outras epistemologias implicam na produção de saberes, valores, atitudes e sensibilidades na perspectiva da emancipação humana.

Contudo, posturas revolucionárias que nos inserem no processo radical de transformação do mundo requerem responsabilidade, direcionamento, determinação, disciplina, objetivos, solidariedade, amorosidade, estar aberto, disponível para firmar a liberdade e o pensamento crítico, vencer a dominação e o autoritarismo, reduzir a obscuridade, refazer a cultura. (FREIRE; SHOR, 2008, p. 127). Assim, revela-se o princípio da indignação ética.

Diante das injustiças socioambientais, este princípio nos atravessa e mobiliza em relação a tudo que afeta negativamente o eu, o outro, o mundo, o que é humano e não humano, ou seja, a cultura, a sociedade, o meio ambiente, a saúde, dentre outros. 0 conhecimento (reflexão crítica) estudos, análise, escuta dos povos conectados com a 
natureza se unem (postura conectiva) para fazer algo dentro de suas possibilidades e necessidades.

Há resistência, luta, ora com armas de ordem social (movimentos sociais) e/ou jurídica (leis, processos, políticas públicas, regulamentos, etc.). Enfrentamento com aquilo que os dominadores temem (perda de bens versus empoderamento), mas também com criatividade, por meio de atividades sustentáveis por outras práticas motivadas por uma desestabilização cultural de pertencimento. Esse princípio articula transformar e ser transformado, ao sermos tocados pelas questões de uma população historicamente explorada e oprimida.

Nesse sentido, indignar-se e refletir criticamente sobre as relações de opressão e submissão, motiva sentimentos e ações de ruptura com situações contrárias aos princípios da vida em sua plenitude singular, diversa e complementar ao outro. Mobiliza outras relações de dialogia não opressora e julgadora que supera a negação do outro pela inversão da prioridade ao outro que me antecede (sujeito ético), experienciado pela força da amorosidade (postura conectiva/intencionalidade transformadora). (GUIMARÃES, et alli. 2020).

A partir da presença provocativa desses princípios em um ambiente educativo/formativo, acreditamos que educadores assim formados e formadores de outros educadores, terão maiores condições de implementar em suas práticas pedagógicas, ações melhor alicerçadas para o enfrentamento da crise civilizatória. Nessa conjuntura, cabe dizer que enquanto formação específica esta ideia tem sido oferecida somente no nível da pósgraduação, apesar da legislação brasileira apontar que a EA deve ser oferecida em todos os níveis e modalidades de ensino.

Dessa forma, contemplamos os anseios pela superação do paradigma hegemônico de tendência conservadora de Educação Ambiental, que guia e engessa a formação de educadores nas universidades, negando a práxis educativa e inspirando práticas ingênuas, fragilizadas e perversas no cotidiano escolar, incapaz de superar a crise ambiental.

Nesse sentido, propor uma estrutura de caráter radical, em termos psicanalíticos utilizado por Marcuse (2018, p. 194-195) que define "uma preponderância no indivíduo dos instintos de vida sobre os instintos de morte", para a formação do educador ambiental, por 
meio de experiências interculturais significativas vividas e sentidas, poderá ser potencialmente capaz de instituir novos modos de viver e estar no mundo. Aprender conhecimentos que devem ser compartilhados e proporcionados à formação de outros educadores ambientais pelo exercício da dialogicidade de novas relações conectivas com o outro, com o mundo e a partir de outro paradigma que supere os limites de uma concepção que mascara ou perpetua o paradigma disjuntivo.

A proposta teórico-metodológica ComVivência Pedagógica é, portanto, um processo formativo, que mescla teoria e prática e não se trata de um momento só da experiência. Nesse processo, há uma preparação anterior que nada mais é do que uma discussão teórica, ou seja, pensar uma forma de fazer a formação do educador ambiental, baseada em concepções teóricas definidas a priori.

Deliberamos, então, a concepção de formação quando pautamos nossa discussão na educação ambiental crítica, transformadora e emancipatória. Toda a discussão emerge para dar subsídio teórico sobre qual visão de educação ambiental trabalhamos.

A preparação para uma vivência diferencial, mais radical, se coloca como parte fundamental para suprimir julgamentos, pré-conceitos, expectativas e críticas sem fundamentos ou baseadas no senso comum. Essa preparação enriquece a experiência e permite compreender melhor o que está por vir. Tira-nos da posição "turista curioso" ou "sabe tudo" para aprender com o outro, com empatia, simplicidade e humildade.

A maior intencionalidade de um processo formativo não deveria ser a de avaliar o que mudou, em termos comparativos, "o que sabia antes e o que sabe depois", mas perceber diferenças nos diálogos, na atitude de questionar mais, na coragem para rever as relações humanas, bem como teorias e práticas estabelecidas.

A formação se dá em grupo e, para realizar a experiência, as pessoas precisam se sentir pertencentes ao grupo. Uma experiência compartilhada atravessa-nos de forma diferente daquela de quem passa por um processo sozinho. Nessa perspectiva, a ideia de participação coletiva se justifica porque somos seres sociais e vivemos coletivamente. $\mathrm{O}$ coletivo se protege com estratégias, isso é imanente da nossa espécie que não sobreviveria individualmente. Portanto, enquanto seres sociais, essas experiências têm que ser 
fundamentadas para pensar a transformação da sociedade, ou seja, pensar a transformação do todo, como indivíduo, na sociedade, buscando outra realidade.

Por isso, a preparação é crucial à experiência, de uma forma que possa ser, de fato, significativa para os participantes.

\section{Sobre ambiente educativo, experiência significativa e Ser mais ambiental}

Conforme já mencionamos, o ambiente educativo é objeto fundante da ComVivência Pedagógica e, apesar de não ser rigidamente definido em suas características, possui alguns aspectos imprescindíveis, como o contato com a natureza, outras epistemologias, temporalidades e espaço.

O momento preparatório, ou seja, aquele que antecede à imersão já como ambiente educativo do processo formativo, deve ser considerado fundamental para tornar a experiência significativa. Desenvolver os princípios formativos em atividades pedagógicas, consolidar a participação coletiva conjunta ${ }^{9}$ como grupo e adquirir conhecimento prévio sobre a história, cultura, hábitos, dessa comunidade, os seus problemas e relações com a sociedade moderna, são imprescindíveis. Caso contrário, torna-se uma viagem turística para um lugar distinto daquele onde se vive por um determinado período de tempo, a fim de se divertir, passear, conhecer lugares e culturas diferentes sem nenhuma intencionalidade educativa ou transformadora.

A dinâmica que se institui no ambiente se dá com base nos princípios formativos já estudados, pois são eles os provocadores da experiência e que a tornam significativa e/ou transformadora, individual e coletivamente.

Como desdobramento da opção pedagógica dialógica no processo formativo do educador ambiental, o ambiente educativo de construção do conhecimento e experienciação se dá mediante reflexões e participação entre os sujeitos e dos saberes que os constituem. A realidade dos sujeitos nos seus contextos micro de atuação e macro estrutural em que estão inseridos, permite que o conhecimento construído mediante a

\footnotetext{
9 Em Guimarães (2004a), definiu-se movimento coletivo conjunto como sendo aquele resultante da relação de 1 com 1, superando uma noção reduzida de coletivo como sendo apenas o somatório das partes; o 1 mais 1.
} 
experiência ressignifique os conteúdos apropriados ao longo da formação e socialização dos educadores (GUIMARÃES, 2004b).

É nesse sentido que Guimarães (2004b) propõe a formação do educador ambiental com base na pesquisa formativa, onde essa deve romper com o paradigma hegemônico da transmissão e ser estruturada na construção da relação respeitosa entre Ser HumanoNatureza-Sociedade. Essa perspectiva envolve uma polifonia de saberes em que se parte da premissa que todos os que participam possuem conhecimentos e experiências válidas e são capazes de aprender e refletir sobre eles, bem como ao vivenciar aprender mais e produzir novos conhecimentos, pois são sujeitos pesquisadores.

Uma questão fundamental sobre a experiência, conforme a definição de Larossa (2002) é que ela precisa ser preenchida de sentido que mobilize a todos tornando-a significativa. Por isso, ao longo do processo formativo, por meio da imersão vivencial ${ }^{10}$, o tempo todo deve-se buscar construção de sentidos em um ambiente que se constitui educativo, como estratégia pedagógica da proposta da ComVivência.

Portanto, todas as atividades que dinamizam o processo educativo possuem intencionalidades, ou seja, não são meras brincadeiras, jogos, práticas para passar o tempo, mas possuem relação direta com os princípios provocadores constituindo a dinâmica do ambiente educativo de forma que ele seja um indicador, uma referência de provocação do movimento, das relações que vão acontecer durante todo o processo.

Assim, podemos sintetizar que o ambiente educativo constitui-se de reflexão com imersão, sendo um espaço-tempo dinamizado por relações provocativas, incentivada por princípios formativos para potencializar experiências significativas sincronicamente vivenciais do indivíduo, de um com o outro indivíduo na sociedade (esse seria o indivíduo e a sociedade, o indivíduo enquanto sociedade) e de um com o outro mundo, ou seja, o mundo com natureza.

Todas as propostas devem ter na ação vivenciada e reflexiva a intenção de romper com a armadilha paradigmática e superar o agir no automático, o que resulta na práxis

\footnotetext{
${ }^{10}$ Consideramos imersão vivencial como um movimento de experimentar o choque de realidade em um ambiente educativo vivenciado com o outro, em comunidade e natureza, a partir de um modo de vida diferenciado por relações outras, diversas ao modo de vida da modernidade.
} 
formativa da experiência vivencial de um ambiente constituído com a finalidade de desenvolver a potência do educador como um Ser mais ambiental. Esse é o educador incompleto e em um mundo inconclusivo, em permanente transformação, que por sua práxis transformada nos processos transformadores da realidade, dinamiza e potencializa movimentos contra hegemônicos na sociedade, na intenção da construção de outros modos de vida em busca da sustentabilidade socioambiental. Eis um educador transformado e transformador em movimento.

Então, para superar uma experiência meramente informativa, onde nos posicionamos como consumidores da situação (como a atitude de um turista) é preciso preparo e acesso a outra perspectiva, na qual se pode ter uma vivência com outra abordagem. Essa vivência se dá em um ambiente educativo intencional para formar educadores ambientais, numa perspectiva mais radical. Portanto, precisa trazer a criticidade na constituição da práxis (ação e reflexão) com a finalidade de transformar e ser transformado, tornar-se um Educador mais ambiental.

\section{Processos inconclusos e em andamento}

A partir dos relatos de diferentes experiências em processos formativos já realizados em nosso grupo (GEPEADS), das consolidações conceituais decorrentes das sínteses apresentadas e diálogos estabelecidos emergem alguns sentidos aos saberes que tramam o desenvolvimento da ComVivência Pedagógica. Assim percebemos algumas pistas que neste trabalho apresentamos sem serem conclusivas, como contribuições para práticas propostas.

Das que antecede a imersão, podemos destacar a preparação como um momento que se dá em dois aspectos, o primeiro pela formação teórica e o segundo pela integração (para imersão) entre as pessoas que vão participar. Aqui se desenvolve relações no espírito da horizontalidade, da amorosidade e solidariedade. A escolha do ambiente deve estar pautada na noção de "o mais natural possível", ou seja, o ambiente físico tendo como característica a intervenção equilibrada dos seres humanos com a natureza deve ser cercado por árvores, lagos ou rios, sem aglomeração urbana, poluição visual e auditiva. Essa configuração tem como finalidade aproximar Ser humano e natureza estabelecendo uma comunicação outra com o ambiente externo. 
A dinâmica nesse ambiente deve pautar-se em ações coletivas, pois mesmo que os processos ocorrerem no interior de cada um, eles acontecem no e com o coletivo; ou seja, numa participação ativa, conjunta, de intensa interlocução, em todos os momentos, do encontro prévio, a experiência imersiva, aos encontros posteriores. Recorre-se à potência do coletivo para transformar. Ainda na perspectiva da organização do ambiente, destacamos $a$ alimentação, a qual têm por característica a simplicidade em todas as refeições, à base de frutas, legumes, verduras e grãos. Portanto, pauta-se em um tipo de nutrição saudável, de fácil preparo, armazenamento e consumo. Além disso, está associada à ideia de purificação do corpo para mantê-lo mais sutil e com disposição. Portanto, evita-se a ingestão de carne, refrigerante, produtos industrializados e outros alimentos ricos em açúcar, sal ou gordura saturada, vivenciando a possibilidade de um outro modo de alimentação.

Estas diretrizes devem estar alinhadas com todos, repercutindo em uma conectividade entre pessoas e com tudo que nos cerca. Para desenvolver esse conceito, requer dos sujeitos uma postura aberta, receptiva ao novo. Saírmos da zona de conforto. Superamos o medo do desconhecido e nos permitimos estar naquele ambiente pelo tempo determinado sem pressa de retornar às atividades do cotidiano. Aqui cabe complementar com a indicação de práticas de meditação e abster-se totalmente do uso de tecnologia para perceber e provocar mudanças internas.

A intencionalidade também se constitui em um preceito importante, pois a experiência deve ser vivida, ao menos, com intenção de transformação (individual e coletiva), a partir das dinâmicas de (re)conexão, expansão da consciência/liberação do ego. Uma oportunidade de rever as posturas individuais no modo de vida da modernidade. Nesse contexto, de entrega e cheio de intenção, ocorre o choque de realidade, no qual propicia, em uma imersão, uma intensa vivência que possibilita experiências significativas. Um tempo e espaço outro vivido, diferente do cotidiano. Permitir-se romper com o uso de aparatos tecnológicos (celular), estabelecendo outras relações com o outro e com o mundo.

Outro ponto observado nesses processos formativos está relacionado a sacralidade, no sentido de reverenciar as dimensões que nos transcendem, estabelecendo relações sacralizadas com o outro (humanos, não humanos, natureza), que estabeleça na atitude de humilde respeitosa e generosa atitudes conectivas com o diferente e algo que nos é maior. 
Sagrados que permitem conexões transcendentais. Respeito a todas as entidades vivas como parte e parcela de algo que nos é maior e nos transcende. Reconhecer a divindade que está em cada um de nós e na natureza, como uma dimensão do sagrado.

Diante de uma fogueira, rememoramos nossos antepassados, as atitudes colaborativas para além das competitivas que levou a nossa ancestralidade a conseguir chegar como espécie até os dias atuais. A cura nas plantas e nos elementais da natureza que consagrou o caminho humano e permitiu a existência de cada um de nós até o presente.

E por falar em presente, desenvolver a capacidade meditativa de transformar angústias em reflexões, olhando para si e observando pensamentos, sem julgamentos, estar e aceitar seu próprio corpo, deixar cair máscaras, condicionamentos, padrões estabelecidos pelos excessos do ego requer de nós solitude, em uma temporalidade onde tudo é relativo e provisório.

Uma atividade que está sujeita às limitações do tempo passado causa depressão, enquanto o olhar em demasia para o futuro como algo pré determinado gera ansiedade. Viver o tempo presente, aceitar o futuro como campo de possibilidades, a dinâmica natural das coisas, do lugar, torna-o prolongado e calmo. Por isso, nos cabe observar e superar, aprendendo a lidar com o que é ou com o que se apresenta intricado, obscuro: dor, medo, dúvidas, impaciência, condutas, pensamentos, ou seja, tudo aquilo que traz desconforto, buscando lidar com tais questões numa perspectiva diferente.

Como continuidade, devemos compartilhar o que temos essencialmente de melhor: escuta, amor, abraço, zelo. Provocar bons sentimentos, alento para corpo e alma e como dizia o Profeta Gentileza, "gentileza gera gentileza".

A finalização de um trabalho nos tem sido estímulo para a permanente reflexão dos saberes desvelados e num processo permanente de pesquisa formação, nosso grupo vem caminhando e buscando nos formar e formar educadores ambientais transformados e transformadores. Esse aqui finalizado é o passo do momento atual. Esperamos contribuir com subsídios para uma caminhada conjunta de todos aqueles que acreditam que, assim como Freire, a Educação sozinha não transforma o mundo, mas sem ela também não há transformações e diante da grave crise mundial, transformações urgem! 


\section{Referências}

ALMEIDA, Marta Pereira de. BARZANO, Marco Antonio Leandro. BASTOS, Dilza Bispo. MELO, André Carneiro. Saberes da biodiversidade: tecendo trilhas e traçando os caminhos que atravessam a escola e o Sertão In: Anais IX Encontro Pesquisa em Educação Ambiental EPEA. Juiz de Fora, 13 a 16 de ago. 2017. Disponível em:

<http://epea.tmp.br/epea2017_anais/list/> Acesso em: 20 set. 2019.

BAUMAN, Zigmunt. Modernidade Líquida. Rio de Janeiro: Jorge Zahar Editor, 2001.

BAUMAN, Zigmunt. Amor líquido: sobre a fragilidade dos laços humanos. Rio de Janeiro: Jorge Zahar Editor, 2004.

CANDIDO, Rejane Leal. MATTIOLI, Camila Kazumi Kitamura. KATO, Danilo Seithi. As Discussões Acerca da Sustentabilidade e Desenvolvimento Sustentável na Perspectiva Intercultural: análise da produção acadêmica a partir do banco de teses do projeto EArte. In: Anais IX Encontro Pesquisa em Educação Ambiental - EPEA. Juiz de Fora, 13 a 16 de ago. 2017. Disponível em: <http://epea.tmp.br/epea2017_anais/list> Acesso em: 20 set. 2019.

CARVALHO, Isabel Cristina. Educação Ambiental: a formação do sujeito ecológico. 5a ed. São Paulo: Cortez, 2011.

CARVALHO, Isabel Cristina. O Sujeito Ecológico: a formação de novas identidades culturais e a escola. In: Pernambuco, Marta; Paiva, Irene. (Org.). Práticas coletivas na escola. 1ed. Campinas: Mercado de Letras, 2013, v. 1, p. 115-124. Disponível em:

http://repositorio.pucrs.br/dspace/bitstream/10923/8680/2/0 sujeito ecologico a formac ao de novas identidades culturais na escola.pdf> Acesso em: 28 mar. 2018.

CASTOR, Katia Gonçalves. Educação Ambiental na Umbanda. In: Anais X Encontro Pesquisa em Educação Ambiental - X EPEA. Aracajú, 1 a 4 de set. 2019. Disponível em: <http://epea.tmp.br/epea2019 anais/list/>Acesso em: 25 set. 2019.

CRUZ, Evandro Cesar Azevedo da. GUIMARÃES, Mauro. O encontro epistemológico e a Chave de Harmonia: A juventude urbana do Santo Daime e suas interações na educação formal. In: Anais IX Encontro Pesquisa em Educação Ambiental - EPEA. Juiz de Fora, 13 a 16 de ago. 2017. Disponível em: <http://epea.tmp.br/epea2017_anais/list> Acesso em: 20 set. 2019.

CRUZ, Evandro Cesar Azevedo da. Pedagogia Decolonial do Santo Daime: referências à psicoativação em ambientes educativos. 2019; Tese (Doutorado em Programa de Pós Graduação em Educação - PPGEduc) - Universidade Federal Rural do Rio de Janeiro, 2019.

EDER, Sofia. A bioconstrução como um potencial dinamizador de relações na formação de educadores ambientais críticos: um modo de edificar um religare em novas sociedades 
possíveis. 2021. Dissertação (Mestrado em Educação, Contextos Contemporâneos e Demandas Populares) - Universidade Federal Rural do Rio de Janeiro, 2021.

FARIA, Jeniffer de Souza. Pesquisa-formação em educação ambiental on-line: experiências e saberes em rede. 2021. 212f. Tese (Doutorado em Educação) - Universidade Federal Rural do Rio de Janeiro, Seropédica, 2021.

FREIRE, Paulo. SHOR, Ira. Medo e Ousadia: O Cotidiano do Professor. Rio de Janeiro: Paz e Terra, 2008.

FREIRE, Paulo. Pedagogia do Oprimido. Rio de Janeiro: Paz e Terra, 2016.

FRIGOTO, Gaudêncio. CIAVATTA, Maria. Educação Básica na década de 1990: subordinação ativa e consentida à lógica do mercado. Revista Educação e Sociedade., Campinas, vol. 24, n. 82, abril 2003. p. 93-130.

GRANIER, Noeli Borek. Experiências de "Comvivência Pedagógica" a Partir de Outras Epistemologias em Processos Formativos de Educadores Ambientais. 2017. $168 \mathrm{f}$. Dissertação (Mestrado em Educação) - Universidade Federal Rural do Rio de Janeiro, Seropédica, 2017.

GUIMARÃES, M. Educação Ambiental Crítica. In: Philippe P. Layrargues. (Org.). Identidades da educação ambiental brasileira. 1aed.Brasília: Ministério do Meio Ambiente, 2004a, p. 2534.

GUIMARÃES, Mauro. A formação de educadores ambientais. Campinas: Papirus, 2004b.

GUIMARÃES, Mauro. GRANIER, Noeli Borek. Educação Ambiental e os Processos Formativos em Tempos de Crise. Rev. Diálogo Educ., Curitiba, v. 17, n. 55, p. 1574-1597, out./dez. 2017. Disponível em:

<https://periodicos.pucpr.br/index.php/dialogoeducacional/article/viewFile/22304/22531> Acesso em: 20 mar. 2019.

GUIMARÃES, Mauro. GARNIER, Noeli Borek. KLEIN, Angela Luciane. Educação Ambiental na "ComVivência Pedagógica" do Caminho de Santiago. Revista Sergipana de Educação Ambiental, v. 9, p. 1-12, 2020.

GUIMARÃES, Mauro. MEDEIROS, Heitor Queiroz de. Outras epistemologias em educação ambiental: o que aprender com os saberes tradicionais dos povos indígenas. Revista do PPGEA/FURG-RS. Ed. Especial, julho/2016, p. 50-67.

LARROSA, Jorge. Notas sobre a experiência e o saber de experiência. Revista Brasileira de Educação, n. 19, p. 20-28, 2002. 
LOUREIRO, Carlos Frederico Bernardo. Educação Ambiental e "Teorias Críticas". In: GUIMARÃES, Mauro (Org.). Caminhos da Educação Ambiental: da forma à ação. CampinasSP: Papirus, 2020.

MARCUSE, Herbert. "Ecologia e crítica da sociedade moderna". Trad. Fernando Bee. Dossiê Herbert Marcuse, Parte 2. Dissonância: Revista de Teoria Crítica, v. 2, n. 1. 2, p. 190-203, junho de 2018.

MATURANA, Humberto. Emoções e linguagem na educação e na política. Belo Horizonte: UFMG, 2002.

MORIN, Edgar. Complexidade e ética da solidariedade. In: CASTRO, Gustavo de; et al. Ensaios de complexidade. Porto Alegre: Sulina, 1997.

NUNES, Franciane Torres dos Santos. ComVivência Pedagógica no Quilombo Santa Rita do Bracuí, outras epistemologias no processo formativo de educadores ambientais. 2019. Dissertação (Mestrado em Educação) - Universidade Federal Rural do Rio de Janeiro, Seropédica, 2019. 